\title{
Current Osteosynthesis Methods in Secondary Osteoporotic Fractures
}

\author{
Păiușan Mihai Gheorghe ${ }^{1}$, Apostu Dragoș ${ }^{1 *}$ Păiușan Petronela Laura ${ }^{2}$, Oltean-Dan Daniel ${ }^{1}$, Benea \\ Horea $^{1}$, Dan Paul Cristian ${ }^{1}$ and Tomoaia Gheorghe ${ }^{1}$ \\ ${ }^{1}$ Department of Orthopedics and Traumatology, University of Medicine and Pharmacy "Iuliu Hațieganu" Romania \\ ${ }^{2}$ Department of Radiology, University of Medicine and Pharmacy "Iuliu Hațieganu" Cluj-Napoca, Romania
}

*Corresponding author: Apostu Dragoș, Department of Orthopedics and Traumatology, University of Medicine and Pharmacy

"Iuliu Hațieganu" Cluj-Napoca, Romania

\section{ARTICLE INFO}

Received: 幽 November 15, 2019

Published: 幽 November 26, 2019

Citation: Păiușan Mihai Gheorghe, Apostu Dragoș Păiușan Petronela Laura, OlteanDan Daniel, Benea Horea, Dan Paul Cristian, Tomoaia Gheorghe. Current Osteosynthesis Methods in Secondary Osteoporotic Fractures. Biomed J Sci \& Tech Res 23(2)2019. BJSTR. MS.ID.003866.

\section{ABSTRACT}

Osteoporosis is a systemic disease characterized by low bone mass and microarchitecture deterioration of bone tissue, things that lead to bone fragility and susceptibility to fracture. Secondary osteoporosis has an underlying cause, a specific disease or disorder but can also occur after hormonosupressive therapyin prostate cancer in men and breast cancer in women. Up to $60 \%$ of men and $20 \%$ of women presenting to specialists with osteoporosis have the secondary type of the disease. Osteoporosis related changes in mechanical properties of bone are often leading to fracture fixation failures. Implant migration and cut-out screws are common in osteoporotic bone. Another issue of concern is severe fracture comminution which complicates fracture fixation. We searched for the articles in the PubMed and Science Direct database using various combinations of terms like "secondary osteoporosis", "secondary osteoporotic fractures", "surgical treatment", "management", "osteosynthesis", etc. to highlight the best surgical treatment options for secondary osteoporotic fractures. Although a "golden standard" treatment does not exist yet, the materials with the best results used in these fractures are the locked plates and intramedullary nails. Bone augmentation and systemic Antiosteoporotic drugs can improve the treatment.

\section{Introduction}

Osteoporosis is a systemic disease characterized by low bone mass and microarchitecture deterioration of bone tissue, things that lead to bone fragility and susceptibility to fracture [1]. Osteoporosis can be primary and secondary. Primary (idiopathic) osteoporosis refers to postmenopausal and age-related osteoporosis while secondary osteoporosis has an underlying cause, a specific disease or disorder [2]. Secondary osteoporosis can also occur after hormone-suppressive therapy in prostate cancer in men and breast cancer in women. Up to $60 \%$ of men and $20 \%$ of women presenting to specialists with osteoporosis have the secondary type of the disease $[2,3]$.

A fracture on secondary osteoporotic bone is affecting the life quality of those patients and is exposing them to further fractures. The treatment for these types of fractures is very challenging and is implying great costs $[4,5]$. There are 2 treatment methods for these types of fractures, conservative and surgical, we will describe in the following lines the surgical treatment.

\section{Method}

For this mini review, we searched for the articles in the PubMed and Science Direct database using various combinations of terms like "secondary osteoporosis", "secondary osteoporotic fractures", "surgical treatment", "management", "osteosynthesis", "materials", "stability", "biomechanical", "osseointegration" and "complications". A number of 29 articles related to the subject were included in to our mini-rewiev.

\section{Results}

\section{General Principles}

The bone's strength and stiffness in osteoporosis are altered, making it even more susceptible to mechanical failure [6,7]. 
Osteoporotic fractures occur more frequently in metaphyseal regions. Osteoporosis related changes in mechanical properties of bone affect the stability of osteosynthesis constructs $[6,8]$. This often leads to fracture fixation failures. It is known that the holding power of the screw is decreasing with shrinking bone density and this is happening especially for nonlocking screws $[9,10]$. Therefore, implant migration and cut-out screws are common in osteoporotic bone. Another issue of concern is severe fracture comminution which complicates fracture fixation $[9,11]$. Patient's characteristics, type of fracture, biomechanical factors and soft tissue envelope are the most important factors to care about for surgical success and choosing the appropriate fixation method [6-11].

\section{Plate Fixation}

The stability of the plate-screw construct is affected by the changes the bone undergoes with osteoporosis [6,12]. If the cortical thickness is decreased by $1 \mathrm{~mm}$ the screw's holding power drops by $50 \%(1000 \mathrm{~N})$, resulting a reduced strength of internal fixation $[12,13]$.

Conventional plates and locking plates can be used to treat secondary osteoporotic fractures and the difference between them is the way load is transferred between the implant and fracture fragments [6-13].

Compression plates are classified as load bearing devices in order to achieve fracture stability through the friction forces between the plate and bone. Friction in conventional plating is obtained by tightening the screws and compressing the plate to the bone [9-14]. The amount of preload on the bone around the screws induced by this compression increases the risk of screw pull out [15].

If locking plates are used, the loads are transferred through the screws and the interface between the screw and plate which prevents individual screws to deteriorate and cutting through the bone [16]. It is recommended using longer plates with fewer screws spread over a longer working distance from the fracture to increase the bending resistance and flexibility $[17,18]$. Rigidity of the construct and a large gap between the fragments are the limitations in using of locking plates, which are leading especially to non-union [6-19].

\section{Intramedullary Nailing}

Internal fixation of secondary osteoporotic fractures using intramedullary nails, allows the patients to start early weight bearing movement avoiding important complications due to prolonged immobilization [6-20]. This osteosynthesis method also protects the soft tissues around the fracture site $[20,21]$. Intramedullary nails allow forces to be more equally distributed between the implant and the bone and have a high resistance to bending forces because are closer to the mechanical axis of the bone $[22,23]$.

The metaphyseal areas where the interlocking screws are placed remain the weakest regions of intramedullary nail fixation.
New generations of intramedullary nails include the use of blades instead of screws which have a greater load bearing surface and higher stability [6-9]. A biomechanical study conducted by Ito et al. showed that under axial loading, the usage of a blade-like interlocking device created a construct that was $41 \%$ stiffer and $20 \%$ stronger than constructs with the normal interlocking screws. Another new type of nails with the option of using interlocking screws in multiple planes helped improve fracture stability and decrease the risk of malunion [6-24].

From a biomechanical point of view these new designs are improving the strength and stiffness of the osteosynthesis but some studies show that they fail to assess stability under rotational loading so furthermore studies are necessary [6-25].

\section{Augmentation}

The most important factor that influences the osteosynthesis success is the quality of the bone in the metaphyseal region or the head-neck fragment [9-26]. Secondary osteoporosis results in reduced bone density and this leads to a smaller bone/ implant contact area and a lower stability for the implants. Polymethylmethacrylate (PMMA) and tricalcium phosphate bone cement are bone augments that can be used to increase the anchorage of the implant in cancellous bone [27].

Two major problems in using PMMA are the lack of osseointegration of the cement and the heat development while the cement is hardening, these problems could lead to further deterioration of the osteosynthesis. Tricalcium phosphate, instead, works as a scaffold for the bone progenitor cells and is remodeled into native bone with time and does not affect the surrounding tissues [9-27].

Systemic drugs such as vitamin D, strontium ranelate, biphosphonates, simvastatin is used following implant fixation to improve osseointegration, but their proved efficiency is limited.

\section{Conclusion}

Secondary osteoporosis is a very important health problem nowadays. Surgical treatment of the secondary osteoporotic fractures implies a lot of resources and great costs. The quality of the bone/implant product is affected by the low quality of the bone. A "Golden standard" treatment for secondary osteoporotic fractures does not yet exist. The materials with the best results used in these fractures are the locked plates and intramedullary nails. Bone augmentation can increase the quality of the product. Systemic drugs can be used to improve osseointegration.

\section{References}

1. McCloskey EV, Oden A, Harvey NC, Leslie WD, Hans D, et al. (2016) A Meta-Analysis of Trabecular Bone Score in Fracture Risk Prediction and its Relationship to FRAX; J Bone Miner Res 31(5): 940-948.

2. Bartl R, Bartl C (2016) Assessment of Secondary Osteoporosis. Bone Disorders pp 293-294. 
3. Fitzpatrick LA (2002) Secondary Causes of Osteoporosis. 77(5): 453468.

4. Taxel P, Kenny A (2000) Differential diagnosis and secondary causes of osteoporosis, Clin Cornerstone 2(6): 11-21.

5. Ganda K, Puech M, Chen JS, Speerin R, Bleasel J, et al. (2013) Models of care for the secondary prevention of osteoporotic fractures: a systematic review and meta-analysis. Osteoporos Int 24(2): 393-406.

6. Yaacobi E, Sanchez D, Maniar H, Horwitz DS (2017) Surgical treatment of osteoporotic fractures: An update on the principles of management. Injury 48(7): S34-S40.

7. Simpson AH, Murray IR (2016) Main differences in osteoporotic fracture models: Which should I use? Injury 47(1): S15-S20.

8. von Rüden C, Augat P (2016) Failure of fracture fixation in osteoporotic bone. 47(2): S3-S10.

9. Kammerlander C, Erhart S, Doshi H, Gosch M, Blauth M (2013) Principles of osteoporotic fracture treatment. Best Pract Res Clin Rheumatol 27(6): 757-769.

10. Willett K, Hearn TC, Cuncins AV (1993) Biomechanical testing of a new design for Schanz pedicle screws. J Orthop Trauma 7(4): 375-380.

11. Gruber R, Koch H, Doll BA, Tegtmeier F, Einhorn TA, et al. (2006) Fracture healing in the elderly patient. Exp Gerontol 41(11): 1080-1093.

12. Goldhahn J, Suhm N, Goldhahn S, Blauth M, Hanson B (2008) Influence of osteoporosis on fracture fixation a systematic literature review. Osteoporos Int 19(6): 761-772.

13. Seebeck J, Goldhahn J, Morlock MM, Schneider E (2005) Mechanical behavior of screws in normal and osteoporotic bone. Osteoporos Int 16(2): S107-S111.

14. Bogunovic L, Cherney SM, Rothermich MA, Gardner MJ (2013) Biomechanical considerations for surgical stabilization of osteoporotic fractures. Orthop Clin North Am 44(2): 183-200.

15. MacLeod AR, Simpson AH, Pankaj P (2015) Reasons why dynamic compression plates are inferior to locking plates in osteoporotic bone: A finite element explanation. Comput Methods Biomech Biomed Eng 18(16): 1818-1825.

16. Miranda MA (2007) Locking plate technology and its role in osteoporotic fractures. Injury 38(3): S35-S39.

ISSN: 2574-1241

DOI: 10.26717/BJSTR.2019.23.003866

Apostu Dragoș. Biomed J Sci \& Tech Res

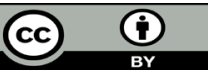

This work is licensed under Creative Commons Attribution 4.0 License

Submission Link: https://biomedres.us/submit-manuscript.php
17. Perren SM, Linke B, Sweieger K, Wahl D, Schneider E (2005) Aspects of internal fixation of fractures in osteoporotic bone. Principles, technologies and procedures using locked plate sckrews. Acta Chir Orthop 72(2): 89-97.

18. Fitzpatrick DC, Doornink J, Madey SM, Bottlang M (2009) Relative stability of conventional and locked plating fixation in a model of the osteoporotic femoral diaphysis. Clin Biomech (Bristol, Avon) 24(2): 203209.

19. Charles C (2005) Fixation consideration in osteoporotic bone fracture. Curr Opin Orthop 16: 376-381.

20. Gardner MJ, Collinge C (2016) Management principles of osteoporotic fractures. Injury 47(2): S33-S35.

21. Hoi W, Miclau T, Chow SK, Yang FF, Alt V (2016) Fracture healing in osteoporotic bone. Injury 47(2): S21-S26.

22. Oltean-Dan D, Dogaru GB, Tomoaia-Cotisel M, Apostu D, Mester A, et al. (2019) Enhancement of bone consolidation using high-frequency pulsed electromagnetic short-waves and titanium implants coated with biomimetic composite embedded into PLA matrix: in vivo evaluation. Int J Nanomedicine. 25(14): 5799-5816.

23. Ito K, Hungerbu R, Wahl D, Grass R (2001) Improved intramedullary nail interlocking in osteoporotic bone. J Orthop Trauma 15(3): 192-196.

24. Horn J, Linke B, Höntzsch D, Gueorguiev B, Schwieger K (2009) Angle stable interlocking screws improve construct stability of intramedullary nailing of distal tibia fractures: A biomechanical study. Injury 40(7): 767-771.

25. Lindner T, Kanakaris NK, Marx B, Cockbain A, Kontakis G, et al. (2009) Fractures of the hip and osteoporosis: The role of bone substitutes. J Bone Joint Surg Br 91(3): 294-303.

26. Heini PF, Franz T, Fankhauser C, Gasser B, Ganz R (2004) Femoroplastyaugmentation of mechanical properties in the osteoporotic proximal femur: A biomechanical investigation of PMMA reinforcement in cadaver bones. Clin Biomech (Bristol, Avon) 19(5): 506-512.

27. Apostu D, Lucaciu O, Lucaciu GD, Crisan B, Crisan L, et al. (2017) Systemic drugs that influence titanium implant osseointegration. Drug Metab Rev 49(1): 92-104.

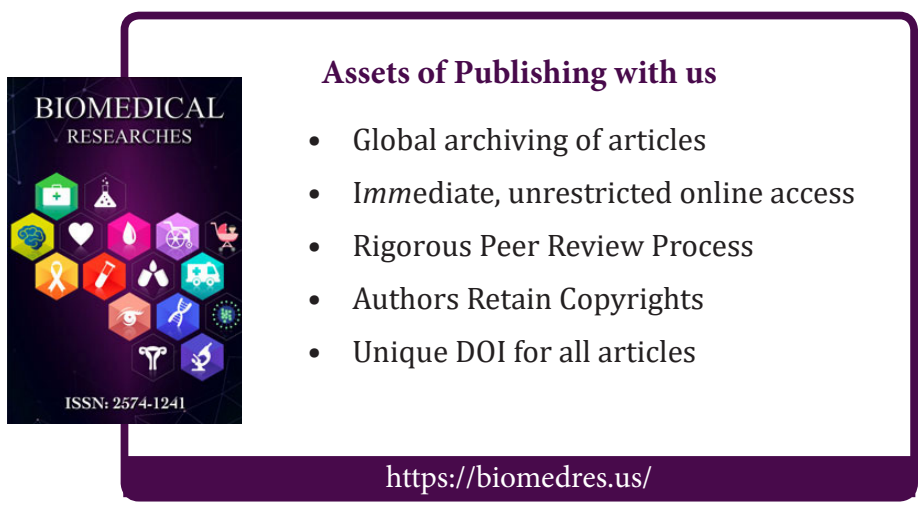

